\title{
Endoscopic Untethering of Tight Filum Terminale: An Operative Technique
}

\author{
Onder OKAY ${ }^{1}$, Ali DALGIC², Ali Erdem YILDIRIM², Melih UCER ${ }^{3}$, Ozhan UCKUN², Serhat BAYDIN², \\ Mustafa Kemal COBAN ${ }^{1}$, Abuzer GUNGOR ${ }^{5}$ \\ ${ }^{1}$ Regional Training and Research Hospital, Department of Neurosurgery, Erzurum, Turkey \\ ${ }^{2}$ Ankara Numune Education and Training Hospital, Department of Neurosurgery, Ankara, Turkey \\ ${ }^{3}$ Kanuni Sultan Suleyman Education and Research Hospital, Department of Neurosurgery, Istanbul, Turkey \\ ${ }^{4}$ Ondokuz Mayıs University, School of Medicine, Department of Neurosurgery, Samsun, Turkey \\ ${ }^{5}$ Yeditepe University, School of Medicine, Department of Neurosurgery, Istanbul, Turkey and University of Health Sciences Umraniye Training \\ and Research Hospital, Department of Neurosurgery, Istanbul, Turkey
}

Corresponding author: Abuzer GUNGOR abuzergungor@gmail.com

\section{ABSTRACT}

AIM: To demonstrate the various technical advantages of minimally invasive endoscopic untethering of tight filum terminale for the treatment of tethered cord syndrome (TCS).

MATERIAL and METHODS: In five pediatric cases of TCS, we performed untethering by using the endoscopic technique. The age of the patients were $6,7,8,9$, and 12 years old. We used a nasal speculum of the transsphenoidal approach during the endoscopic surgical procedure.

RESULTS: All the procedures were performed uneventfully, except for one case with a split cord malformation that showed neurologic deterioration caused by excision of the diastematomyelic fibrous septum at the thoracic level (unrelated to the endoscopic procedure at the L5-S1 level). This patient was referred to a rehabilitation clinic 5 days after surgery and showed significant improvement by the third postoperative month. The other four patients were discharged 1 day after the operation.

CONCLUSION: Endoscopic release of filum terminale is a safe technique especially if it is performed with neuromonitoring. This technique may shorten the length of hospital stay and reduce perioperative blood loss. However, futher studies with a larger number of patients and long-term follow-up are needed.

KEYWORDS: Minimally invasive, Endoscopy, Tethered cord, Filum terminale

\section{INTRODUCTION}

T Tethered cord syndrome (TCS) is a clinical syndrome characterized by radiological and clinical signs. The clinical signs are associated with the stretching of the distal spinal cord (1). The most common clinical signs are sacral dimples, lumbar hair patches, asymmetric gluteal clefts, color alteration of the lumbar skin, back and leg pain, paresthesias in the lower extremities, orthopedic deformities, and urological disorders (12). In affected growing children, increased tension in the spinal cord may worsen the loss of neurological functions over time. Some affected patients could be asymptomatic; in this cases, the condition can be detected only on radiological studies. The treatment of tight filum terminale is untethering of the tight filum terminale.

Open surgical untethering of the spinal cord yields good postoperative results; however, the spinal cord may become retethered, leading to scar formation. The minimally invasive endoscopic technique is associated with minimal tissue trauma, but only a few reports using this technique have been published. Minimally invasive operative techniques could
Onder OKAY (D) : 0000-0002-5566-2437

Ali DALGIC $\quad$ (D) : 0000-0001-8586-0613

Ali Erdem YILDIRIM (D) : 0000-0002-8829-5274
Melih UCER (D) : 0000-0002-2004-2991

Ozhan UCKUN (D) : 0000-0002-3845-2665

Serhat BAYDIN (D) : 0000-0001-9041-7229
Mustafa Kemal COBAN (D) : 0000-0001-7643-7039 Abuzer GUNGOR 
have several benefits, such as decreased reoperation rates, shorter lengths of hospital stay, and reduced perioperative compared with other techniques. In this retrospective cohort study, we aimed to demonstrate various technical advantages of endoscopic untethering in cases of tight filum terminale.

\section{MATERIAL and METHODS}

\section{Patients}

In five pediatric cases of TCS, we performed untethering through the endoscopic technique. The age of the patients were $6,7,8,9$, and 12 years old. Three patients were girls and two were boys. We used a nasal speculum for the transsphenoidal approach during the procedure. This speculum had a modifiable working angle instead of a fixed working channel and it was preferred because the area of vision could be extended by changing the position of the speculum during the operation. This flexibility of the speculum enabled direct visualization of the nerve roots and filum terminale via a minihemilaminotomy and a $1.5-\mathrm{cm}$ dural opening, using a rigid 0 -degree endoscope. We believe that angled endoscopes are usually not necessary while using this flexible speculum. We used perioperative neuromonitoring and neurostimulation to confirm the filum terminale.

\section{Surgical Technique}

All the patients underwent the surgery under general anesthesia in the prone position. Then, we determined the level of tethering by fluoroscopy. An approximately $2-\mathrm{cm}$ long skin incision was made and the paravertebral muscles were dissected in order to visualize the vertebral lamina. When the vertebral lamina was exposed, the nasal speculum was placed into the surgical field. Next, the 0-degree neuroendoscope was placed in the surgical field and the vertebral lamina were inspected. The laminotomy was performed with a high-speed drill (Midas Rex; Medtronic, Fort Worth, TX, USA). The ligamentum flavum was then displaced to easily visualize the dura $\mathrm{c}$. We used perioperative neuromonitoring and neurostimulation to confirm the filum terminale. The dura mater was cut to see the caudal fibers. Nerve root stimulation of the filum was performed, and the bilateral anal sphincter and distal lower extremity were monitored by electromyography. Control stimulation was performed on the L5 and S1 nerve roots to ensure their identification. Once stimulation failed to produce a sphincter electromyographic signal, the filum was cut from the dorsal surface to the center and then to the ventral surface along with alternative stimulation. The dura was closed with watertight sutures (Figure 1A-D).

\section{RESULTS}

All the procedures were performed uneventfully, except for one case who had a split cord malformation that showed neurologic deterioration caused by excision of the diastematomyelic fibrous septum at the thoracic level (unrelated to the endoscopic procedure at the L5-S1 level). This patient was referred to a rehabilitation clinic 5 days after surgery and showed significant improvement by the third postoperative month. The other four patients were discharged 1 day after the surgery. Perioperative blood loss was about 25-45 $\mathrm{ml}$ (30 $\mathrm{ml}$ average) (Table l).

\section{DISCUSSION}

Patients with TCS generally have back and leg pain, weakness, and urologic symptoms (12). This syndrome is thought to be caused by the stretching of the pial vessels and impaired perfusion of neural elements, which in turn, are known to be as a result of mitochondrial oxidative metabolism (15). This hypothesis was supported by the demonstration of increased distal spinal cord blood flow after the release of the tethered spinal cords (9).

The stages of the classical surgical treatment for tethered cord are open laminectomy, midline phylum identification, and separation of related nerve fibers from this structure (13). Endoscopic studies on cadavers have demonstrated that access to the filum terminale is possible $(5,6)$. In the endoscopic approach, midline structures are preserved and a mini-hemilaminectomy is sufficient. The flexibility of the speculum enabled direct visualization.

There are several advantages for using an endoscopic approach: using minimal invasive skin incision (about $2 \mathrm{~cm}$ ) and as a result minimal tissue trauma, which may reduce retethering by scar formation frequently encountered after opening procedures. Also this minimal insizion occure less bleeding $(3,12,14)$. In the study of Potts et al., an average of $300 \mathrm{ml}$ of bleeding was observed with open surgery (7). Significant blood loss and postoperative scarring are also associated with the muscle dissection in this approach $(7,11)$. In our study, patients average blood loss was $30 \mathrm{ml}$.

Cerebrospinal fluid leaks have been reported at $0.9-15 \%$ rates, from after traditional surgical procedures $(2,4,8,10)$. No CSF leak was observed in our patients, who had undergone an endoscopic procedure that we reviewed retrospectively; however, we found that it was technically more difficult to close a dura opened with a tubular retractor than congenitally

Table I: Patient Demographics

\begin{tabular}{ccccc}
\hline Case No. & Age (yrs) & Sex & Blood loss(ml) & Specific MRI findings \\
\hline 1 & 6 & Girl & 25 & fatty filum; no lipoma \\
\hline 2 & 7 & Girl & 30 & diastematomyelia \\
\hline 3 & 8 & Boy & 45 & intradural lipoma; fatty filum \\
\hline 4 & 9 & Girl & 25 & fatty filum; no lipoma \\
\hline 5 & 12 & Boy & 25 & fatty filum; no lipoma \\
\hline
\end{tabular}




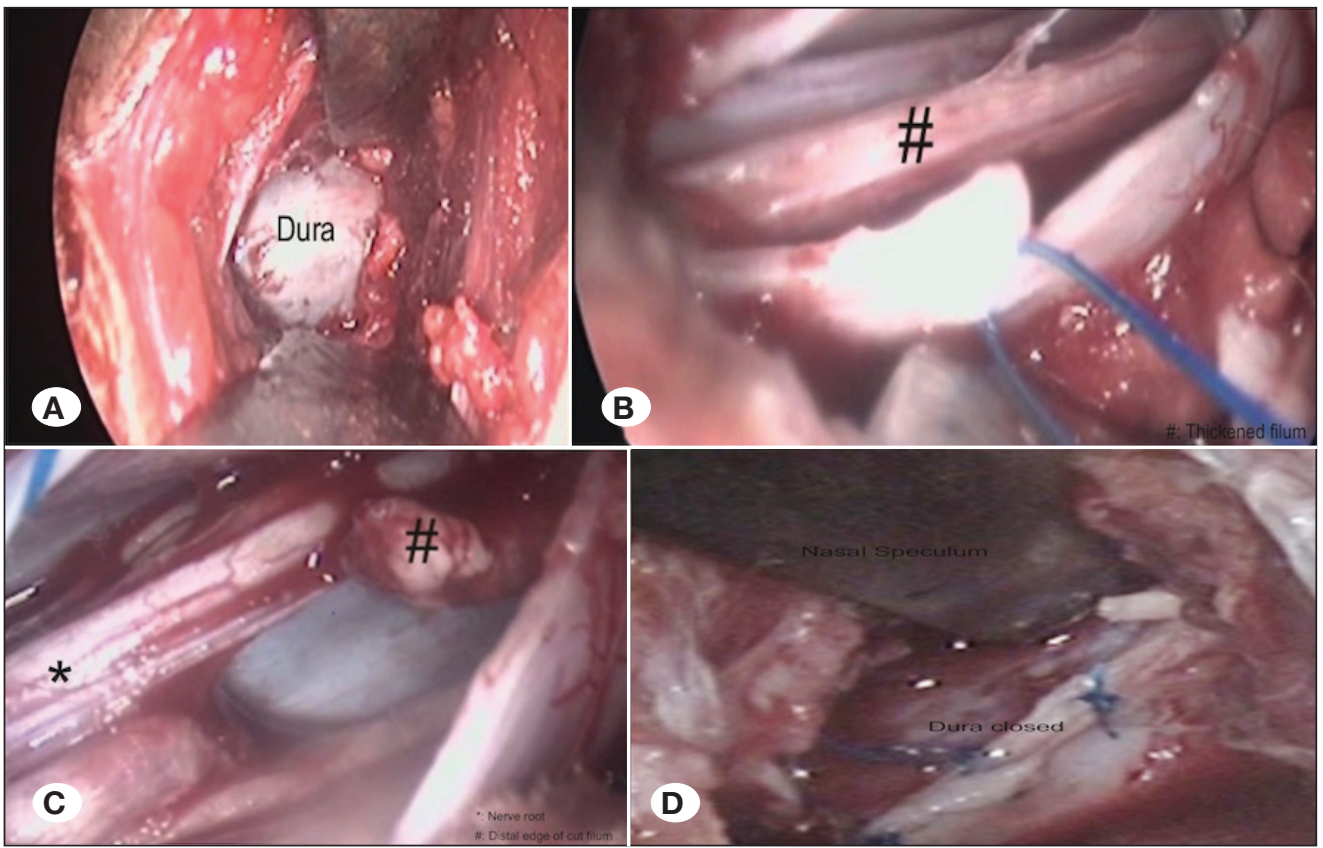

Figure 1: A) The nasal speculum was placed into the surgical field, B) thickened filum, C) the filum was cut from the dorsal surface, D) the dura was closed with watertight sutures.

opened dura. Maximum $1.5 \mathrm{~cm}$ dural opening and minimal tissue damage may theoretically also have the advantage of reducing the risk of CSF leakage.

\section{CONCLUSION}

Endoscopic release of filum terminale is a safe technique especially if it is performed with neuromonitoring. This technique may shorten the length of hospital stay and reduce perioperative blood loss. However, further studies with a larger number of patients and long-term follow-up are needed. Long-term rates of retethering and surgical success should also be investigated. As endoscopic instrumentation and techniques improve, the treatment for a tethered cord can be carried out with minimal complications.

\section{REFERENCES}

1. Bao N, Chen ZH, Gu S, Chen QM, Jin HM, Shi CR: Tight filum terminale syndrome in children: Analysis based on positioning of the conus and absence or presence of lumbosacral lipoma. Childs Nerv Syst 23:1129-1134, 2007

2. Bhimani AD, Selner AN, Patel JB, Hobbs JG, Esfahani DR, Behbahani M, Zayyad Z, Nikas D, Mehta Al: Pediatric tethered cord release: An epidemiological and postoperative complication analysis. J Spine Surg 5(3):337-350, 2019

3. Di X: Endoscopic spinal tethered cord release: Operative technique. Childs Nerv Syst 25:577-581, 2009

4. Lee GY, Paradiso G, Tator CH, Gentili F, Massicotte EM, Fehlings MG: Surgical management of tethered cord syndrome in adults: Indications, techniques, and long-term outcomes in 60 patients. J Neurosurg Spine 4:123-131, 2006

5. Mourgela S, Anagnostopoulou S, Sakellaropoulos A, Koulousakis A, Warnke JP: Endoscopic anatomy of the thecal sac using a flexible steerable endoscope. J Neurosurg Sci 51: 93-98, 2007
6. Mourgela S, Anagnostopoulou S, Sakellaropoulos A, Koulousakis A, Warnke JP: Sectioning of filum terminale externum using a rigid endoscope through the sacral hiatus. Cadaver study. J Neurosurg Sci 52:71-74, 2008

7. Potts MB, Wu J, Gupta N, Mummaneni PV: Minimally invasive tethered cord release in adults: A comparison of open and mini-open approaches, Neurosurgical Focus 29: E7, 2010

8. Rajpal S, Tubbs RS, George T, Oakes WJ, Fuchs HE, Hadley MN, Iskandar BJ: Tethered cord due to spina bifida occulta presenting in adulthood: A tricenter review of 61 patients. J Neurosurg Spine 6:210-215, 2007

9. Schneider SJ, Rosenthal AD, Greenberg BM, Danto J: A preliminary report on the use of laser-Doppler flowmetry during tethered spinal cord release. Neurosurgery 32:214218, 1993

10. Shukla M, Sardhara J, Sahu RN, Sharma P, Behari S, Jaiswal AK, Srivastava AK, Mehrotra A, Das KK, Bhaisora KS: Adult versus pediatric tethered cord syndrome: Clinicoradiological differences and its management. Asian J Neurosurg 13(2):264270, 2018

11. Telfeian AE, Punsoni M, Hofstetter CP: Minimally invasive endoscopic spinal cord untethering: Case report. J Spine Surg 3:278-282, 2017

12. Tredway TL, Musleh W, Christie SD, Khavkin Y, Fessler RG, Curry DJ: A novel minimally invasive technique for spinal cord untethering. Neurosurgery 60 (2 Suppl 1): ONS70-ONS74, 2007

13. Warder DE: Tethered cord syndrome and occult spinal dysraphism. Neurosurg Focus 10:e1, 2001

14. Woods KRM, Colohan ART, Yamada S, Yamada SM, Won DJ: Intrathecal endoscopy to enhance the diagnosis of tethered cord syndrome. J Neurosurg Spine 13: 477-483, 2010

15. Yamada S, Zinke DE, Sanders D: Pathophysiology of "tethered cord syndrome". J Neurosurg 54:494-503, 1981 